\title{
Sobre as Formas Sociais da Mudança Individual: o testemunho em centros de recuperação pentecostais
}

\author{
Cesar Pinheiro Teixeira ${ }^{\mathrm{a}}$ \\ Beatriz Brandão ${ }^{\mathrm{b}}$
}

\begin{abstract}
Este trabalho reúne elementos de duas pesquisas distintas, realizadas pelos respectivos autores sobre centros de recuperação pentecostais. Se, por um lado, a verdade dos relatos de conversão não é questionada pelos pesquisadores, a fim de compreender da forma menos assimétrica possível os valores e as lógicas em jogo; por outro, a verdade da conversão é recorrentemente investigada pelos próprios atores pesquisados. Para boa parte deles, é fundamental saber, por exemplo, quem 'realmente quer mudar' e quem 'se esconde atrás da Bíblia'. Terminam por desenvolver, na prática, algumas formas sociais da mudança individual (uma gramática do testemunho e uma ética da transformação), que lhes auxilia a operar com 'testemunhos autênticos' e 'falsos testemunhos'. As consequências de possíveis confusões possuem relevância sociológica justamente porque sugerem a existência de tais formas. Produzir sujeitos que saibam operar com elas é algo importante para a construção da credibilidade dos centros de recuperação e, principalmente, para a sua expansão.
\end{abstract}

Pentecostalismo, Centros, de recuperação, Comunidades terapêuticas, Testemunho, Ética.

Os analistas que se debruçam sobre a temática da conversão não costumam questionar as narrativas dos atores. Assim procedem porque em geral o que importa não é o valor de verdade das histórias contadas, e sim o que elas ensinam sobre os mundos pelos quais os atores transi-

a Coordenador efetivo de pesquisas do Núcleo de Estudos da Cidadania, Conflito e Violência Urbana (NECVU/UFRJ) e bolsista de pós-doutorado (FAPERJ) do Sociofilo - Colaboratório de Teoria Social e Filosofia (IFCS/UFRJ). Email: cesarpinheiroteixeira@gmail.com.

b Pós-doutoranda do Departamento de Sociologia (USP). Pesquisadora do IPEA. Email: bia.brandao18@hotmail.com. 
tam e sobre os processos sociais que, ao fazê-lo, explicitam. No entanto, se, do ponto de vista analítico, pôr em suspenso o julgamento sobre a verdade dos testemunhos é uma atitude metodológica indispensável para compreender o que comunicam seus conteúdos, da perspectiva dos próprios atores, imersos em sua vida cotidiana, o julgamento acerca do seu valor de verdade é uma prática fundamental. Especialmente no contexto estudado neste artigo, os centros de recuperação pentecostais, ser capaz de distinguir, por exemplo, 'pessoas realmente convertidas' de 'charlatões' é uma prática bastante importante para os envolvidos. As consequências de possíveis confusões possuem relevância sociológica na medida em que sugerem a existência de formas sociais da mudança individual. Produzir sujeitos que saibam operar com essas formas é algo importante para a construção da credibilidade dos centros de recuperação e, principalmente, para a sua expansão.

Um exemplo. Em 11 abril de 2019 foi assinado pelo Presidente da República o Decreto 9.711/2019 aprovando a nova Política Nacional sobre Drogas (PNAD) ${ }^{1}$. Ao ler o decreto, que dá poder de tratamento praticamente exclusivo às comunidades terapêuticas, um dos dirigentes de um centro pesquisado por um de nós escreve animado, e ao mesmo tempo preocupado, com essa ação política:

Até que enfim ele acertou em dar valor ao nosso trabalho, mas agora eu fico preocupado que com tanto dinheiro que vai sair do governo, vai ter um monte de igreja que vai querer montar centro de recuperação só para ganhar dinheiro e envergonhar o trabalho sério que fazemos há tanto tempo.

Essa fala se refere a como esses atores analisam seu próprio trabalho, em constante comparação com outros que procedem nos mesmos fundamentos, pedagogias e racionalidades. Para eles, cada um desses espaços deve produzir testemunhos autênticos a fim de alcançar credibilidade e, com isso, incrementar suas formas de financiamento. A fala do dirigente nos remete, assim, à problemática de que tratamos neste artigo, uma vez que as escalas individual e institucional se encontram entrelaçadas numa complexa teia de reconhecimento da autenticidade das mudanças individuais. Vale a pena lembrar que é muito 
comum os centros de recuperação terem início a partir das próprias trajetórias de mudança individual de suas lideranças

Nesse contexto, a possibilidade da conversão é vivida como uma experiência que desperta bastante desconfiança. De forma geral, há uma forte preocupação com as intenções das pessoas que buscam ajuda nessas instituições. Os dirigentes sempre avaliam as intenções em jogo, isto é, se as pessoas 'querem realmente se recuperar' ou se 'querem apenas se esconder atrás da Bíblia' - construindo, por exemplo, uma fachada de crente capaz de lhes conferir credibilidade em alguns espaços públicos. Neste artigo, debruçamo-nos justamente sobre os modos através dos quais os atores se guiam pelos labirínticos caminhos do reconhecimento da autenticidade de uma mudança individual.

Nossa hipótese tem como ponto de partida a abordagem proposta por Dullo (2013, 2014, 2016a, 2016b), na qual o testemunho é pensado como um campo de investigação que não se esgota na análise do conteúdo de suas narrativas. Dullo desenvolve uma teoria do testemunho na qual este é pensado em sua dimensão psicagógica, ou seja, é pensado como prática capaz de produzir mudanças individuais a partir da narrativa de casos exemplares. Assim, o testemunho não se reduziria à sua forma (a experiência em primeira pessoa) nem ao seu conteúdo (autobiográfico); ele é pensado como uma técnica que orienta determinados processos de subjetivação. Em diálogo com essa abordagem, propomos pensar que a eficácia psicagógica do testemunho está diretamente ligada a uma gramática do testemunho (Teixeira 2016) a partir da qual os atores orientam seus julgamentos acerca da autenticidade de sua própria conversão ou da de outrem.

Para explorarmos essa questão, iremos, em primeiro lugar, apresentar em linhas gerais o contexto empírico do qual partimos, os centros de recuperação pentecostais, descrevendo algumas características fundamentais de nossos trabalhos de campo. Logo após, traremos algumas reflexões sobre como o testemunho opera como uma forma social importante. Em seguida, aprofundamos a análise a partir da exploração de duas questões importantes na construção do testemunho: o orgulho e o sofrimento como pontos sensíveis de uma ética pentecostal da transformação. 


\section{Centros de recuperação}

Em primeiro lugar, é necessário esclarecer o uso das nomenclaturas comunidades terapêuticas (CTs) e centros de recuperação (CRs) (Brandão \& Carvalho 2016). Num escopo legal e de marcos regulatórios, de um modo geral, as residências temporárias, instituições constituídas num modelo de cuidado direcionado a pessoas com usos problemáticos ou abusivos de drogas (Brandão 2019) são todas nomeadas como comunidades terapêuticas. As CTs englobam práticas para tratamentos com o uso de drogas, seja religioso ou de iniciativa laica, e precisam estar dentro de uma regulamentação para poderem concorrer a editais para incentivos fiscais públicos, bem como serem fiscalizadas².

No entanto, uma ampla gama de projetos ligados a igrejas independentes, em sua maior parte pentecostais, são identificados pelos atores em sua nomenclatura como CRs e não como CTs. Apesar de saberem que na linguagem jurídica assim são denominados, reivindicam uma identidade própria, diferenciada da representação mais ampla das CTs. Com base em traços importantes do universo pentecostal, eles avaliam que suas iniciativas vão além das CTs (por eles rotuladas como 'tradicionais'), uma vez que apostam não somente na abstinência do uso de drogas como método de tratamento, mas também na construção de um novo homem. Assim, usaremos, para os limites deste artigo, o termo êmico mobilizado por eles e chamaremos, daqui em diante, de CR e não de $\mathrm{CT}$, cientes da disputa narrativa e política entre essas nomeações e os tipos de instituição que elas representam.

A análise aqui exposta parte dos trabalhos de campo dos autores em dois CRs masculinos, um localizado na Baixada Fluminense (Teixeira 2013, 2016) e outro na Zona Oeste do Rio de Janeiro (Brandão 2017). O primeiro contava com cerca de 100 homens, chamados de alunos. Tratase de um sítio com terreno amplo, um templo, refeitório e dormitório coletivo, que se sustenta a partir de doações, como também pela produção de vassouras e cocadas vendidas nas ruas e no transporte coletivo. $\mathrm{O}$ segundo contava com 400 homens, chamados de hóspedes. Trata-se de um sítio que também se sustenta a partir de doações e do serviço prestado por meio de um lava-a-jato construído dentro desse espaço. 
Os CRs se caracterizam, de forma geral, por receberem um público amplo que, apesar de procurar os centros alegando 'problemas com drogas', constituem um conjunto bastante heterogêneo: usuários radicais que desejam mudar a sua condição; moradores de rua; bandidos que atribuem seu engajamento em atividades criminais ao uso de drogas e desejam mudar de vida; pessoas ameaçadas de morte por traficantes, milicianos e policiais e que são resgatas pelos pastores e obreiros da casa ou que são encaminhadas para lá pelos próprios policiais, traficantes e milicianos como uma alternativa ou uma última chance (genericamente chamados de vacilões).

A entrada na pesquisa de ambos os CRs foi marcada por um ponto em comum. Inicialmente, as lideranças do local escolhiam os residentes (alunos ou hóspedes, a depender do CR pesquisado) com quem poderíamos travar contato, argumentando que nem todos estavam preparados para contarem suas próprias histórias ou mesmo que poderiam 'estragar' a pesquisa com 'testemunhos errados'. De certa maneira, a recuperação proposta pelos CRs (e recuperação é tomada aqui como uma importante categoria nativa) implicava o aprendizado de uma maneira 'correta' ou 'adequada' de contar a própria história aos outros, isto é, implicava o aprendizado de uma certa competência narrativa. A atitude de selecionar os 'melhores entrevistados' não pode ser compreendida a partir de um enquadramento raso que a encerra na produção de uma fachada institucional. Trazemos um exemplo de uma situação ocorrida no CR do Rio de Janeiro:

Caminhando pelas ladeiras do sítio, entre muitos e muitos homens, Malaquias se vira para Davi e diz: "por que não chamamos fulano para a entrevista?" e, sem pensar muito, Davi solta logo: "não, porque ele é 171”. Malaquias aceitou, mas logo deu outra sugestão, que Davi também refutou dizendo ser o outro um mentiroso. Davi, se orgulhava de saber a história de todos os 400, diz quem é mentiroso, quem é '7', quem é verdadeiro, quem tem as trajetórias impactantes, de sucesso ou fracasso.

Cenas como esta, comuns nos CRs, nos indicam que saber distinguir um 'testemunho falso' de um 'verdadeiro' ou distinguir uma 'conversão autêntica' de uma 'conversão falsa' ou ainda saber quem "está pronto para testemunhar" e "quem não está” são habilidades ex- 
tremamente importantes para as lideranças do centro de recuperação, uma vez que isso tem implicações sérias para a construção da reputação e da credibilidade da casa.

\section{Uma visão panorâmica do testemunho nos centros de recuperação pentecostais}

Tomando como referência a filosofia do chamado segundo Wittgenstein, buscamos explorar uma visão panorâmica do testemunho nos CRs estudados. Nós não nos focamos apenas nas narrativas; nos concentramos em alguns aspectos da relação entre diferentes dimensões do testemunho. Isto implica, portanto, trazer à análise seus diferentes usos, mobilizados em diversos contextos e situações, os quais produzem distintos significados. Por isso, o método gramatical wittgensteiniano pode nos auxiliar a tomar um pouco de distância do conteúdo da narrativa biográfica, proporcionando, assim, uma espécie de visão panorâmica do testemunho.

A obra madura do filósofo austríaco, apesar de definida pelo próprio autor como um álbum (Wittgenstein 2011[1952]:166), por conta do estilo aforístico e da abordagem de múltiplos temas distantes entre si, é, na verdade, inteiramente costurada pela construção, ainda que inacabada, de um método gramatical (Marques 2012:14). De forma geral, esse método resulta da revisão crítica que fizera do Tractatus logicus-philosophicus, no qual operava com base em uma concepção essencialista da linguagem, procurando desvelar o que seria sua estrutura básica. Wittgenstein desconstrói sua abordagem inicial a partir de um longo processo de conversão analítica, passando a operar, então, contra essa concepção essencialista, e buscando compreender a complexidade do emaranhado de sentidos que emerge nos múltiplos usos das palavras empregadas em diferentes situações e contextos, isto é, em diferentes jogos de linguagem. No Wittgenstein das Investigações Filosóficas (IF), a linguagem não pode ser reduzida à nenhuma dimensão específica, uma vez que é algo inseparável de um conjunto de atividades.

Nessa segunda fase, o jogo surge como uma metáfora fundamental para que o filósofo austríaco esclareça o caráter irredutível da lin- 
guagem em sua nova concepção. Aqui, o jogo se torna um recurso importante para se lidar com a multiplicidade de sentidos e contextos em que estes são produzidos. Para Wittgenstein, a linguagem funcionaria de uma forma análoga ao jogo. Destacamos dois aspectos básicos: 1) as regras de um jogo são inseparáveis de sua prática (IF, parágrafo 82); e 2) a imensa diversidade de jogos e de suas regras não são redutíveis a um elemento comum e isto não torna a ideia genérica de jogo algo sem sentido: mesmo que haja muito pouco em comum entre o jogo de damas, o futebol e a peteca, faz sentido dizer que todos são jogos (IF, parágrafo 65). A análise da linguagem como conjunto de jogos é o arquétipo do método gramatical das Investigações. Não por acaso, a análise de diversos jogos de linguagem constitui a atividade básica do livro. Para o filósofo austríaco, o uso das palavras em determinados jogos de linguagem nos permite uma compreensão muito mais rica da produção de sentidos do que sua antiga concepção essencialista, que deixava de fora de seu escopo analítico uma grande parte dos problemas que enfrentava.

A metáfora do jogo é o núcleo do método gramatical, construída a partir de uma associação diádica fundamental (uso-regra) que nos permite esclarecer os caminhos labirínticos da produção de sentidos e das formas de compreensão, atenta à relação complexa e intrincada entre as escalas mínimas das proposições e as escalas máximas das formas de vida. Ao descrever inúmeros jogos de linguagem, Wittgenstein busca desfiar o complexo emaranhado de sentidos, por meio da análise de diferentes usos, decodificando e explicitando, ao mesmo tempo, as regras que tecem sua formação.

É por essa razão que o próprio Wittgenstein define seu livro como um álbum. Ele aplica seu método gramatical a uma ampla gama de questões, como as de lógica, de matemática e de estados de consciência (Wittgenstein 2011[1952]:166) por meio da descrição de um sem -número de jogos de linguagem. No entanto, mais que um inventário de tais jogos, o filósofo busca a construção de uma compreensão do funcionamento da linguagem capaz de dar conta da multiplicidade irredutível dos usos. Seu objetivo era que essas descrições viessem a constituir - por meio da análise de aproximações e de distanciamentos, de 
suas semelhanças e de suas diferenças - um übersicht (uma perspectiva panorâmica, uma visão panorâmica) do funcionamento da linguagem (Marques 2012:14). Contudo, o prólogo escrito em 1946 para o conjunto de manuscritos que posteriormente veio a ser batizado por seus herdeiros intelectuais como as Investigações filosóficas deixa entrever que o filósofo julgava não ter alcançado seu objetivo. Mesmo assim, sua busca produziu um método - de caráter aberto, por fazer - que se propõe, de uma forma mais geral, ser capaz de nos fazer compreender a complexidade da multiplicidade sem reduzi-la a uma única dimensão fundamental. E mais: que se propõe a nos fazer compreender os movimentos possíveis por entre essas múltiplas dimensões.

Nos CRs estudados, o testemunho é pensado como uma prática que ganha sentidos distintos em pelo menos três situações diferentes, analisadas a partir das expressões nativas 'ter', 'dar' e 'ser o testemunho'. Propomos que essas diferentes dimensões do testemunho produzem uma espécie de gramática do testemunho (Teixeira 2016). Em primeiro lugar, há a ideia de que o testemunho é algo que se tem. 'Ter o testemunho' significa possuir uma história de transformação, isto é, significa ter vivenciado uma série de eventos e emoções que caracterizariam e justificariam a sua transformação. Em segundo lugar, há a ideia de que o testemunho diz respeito a uma performance pública. 'Dar o testemunho' é a ação de performatizar a sua narrativa biográfica de transformação a uma audiência. Por fim, há também a ideia de que o testemunho implica assumir um compromisso com a história contada publicamente. 'Ser o testemunho' diz respeito à expectativa de coerência, na vida cotidiana, entre a narrativa apresentada ao público e as ações daquele que testemunha.

Propomos, então, pensar o testemunho como uma prática tridimensional na qual se articulam a construção de uma narrativa, sua performance e a sustentação do seu conteúdo nas interações cotidianas. Na gramática pentecostal do testemunho operada nos CRs pesquisados, não basta ter um testemunho para contar; é necessário sê-lo, isto é, comprometer-se com a própria narrativa construída, dando provas de que a transformação narrada é uma prática cotidiana, para que 
sua performance seja considerada autêntica e produza a valorização moral da pessoa. Saber operar com essa gramática é fundamental para a vida cotidiana nos CRs, tanto para alunos/hóspedes quanto para os pastores e para os obreiros. Nesse contexto, a dimensão performativa do testemunho não pode ser analisada de forma isolada, pois ela está completamente atravessada pelas relações, interações e situações que compõem o cotidiano do centro de recuperação. Portanto, propor a análise de uma gramática do testemunho implica pensar o testemunho como uma forma social através da qual as mudanças individuais podem ser socialmente construídas e também avaliadas: os limites e as possibilidades da conversão.

No CR de Magé, os alunos contavam muitas histórias sobre como o uso de crack seria a principal explicação para a conduta dos chamados 'vacilões'. Um dos alunos, que havia ocupado uma função importante num grupo de narcotraficantes de uma favela no município do Rio de Janeiro, contou um caso no qual um usuário de crack teria roubado cem reais de uma criança. Seu chefe ordenou a ele e a seus parceiros que fossem atrás do ladrão, recuperassem o dinheiro e o castigassem severamente. $\mathrm{O}$ ex-traficante narrava com empolgação a sua história: "e aí nós saímos tudo de peça (armas de fogo) atrás daquele vacilão”. De repente para, abaixa a cabeça, faz uma feição envergonhada. Alguns segundos de silêncio quebram o ritmo da narrativa. E diz: "eu não posso contar isso dessa forma, pois agora eu sou um novo homem em nome de Jesus". Depois o procurei para saber detalhes da mudança súbita. Disse que ao narrar o caso daquele modo ele "não estava dando testemunho, estava mais parecendo um bandido com saudade da sua vida, e não um cristão dando testemunho".

O rapaz julga que agiu de forma equivocada, o que poderia ter posto em questão a autenticidade de sua conversão perante os demais presentes. Esse breve relato mostra que a gramática pentecostal do testemunho pode ser pensada como um conjunto de usos e de regras que não se esgotam em uma dimensão lógica; possui também uma série de implicações éticas. Neste texto, sugerimos pensar que gramática do testemunho é uma forma social importante para a regulação e a 
autorregulação das conversões. Desse modo, a conversão poderia ser pensada como um jogo de linguagem que precisa ser aprendido para que seja reconhecida em sua autenticidade.

O relato nos indica a existência de formas contextuais certas e erradas que regulam tanto o recurso mental à memória quanto a sua exposição pública. Assim, a utilização da memória para a construção do testemunho é algo que precisa necessariamente se distanciar do que teria sido a experiência original ao mesmo tempo em que se alimenta dela. Na gramática pentecostal do testemunho que atravessa a vida cotidiana dos CRs, rememorar não pode se confundir com reviver. Ao classificar a forma como estava narrando sua própria história ("como um bandido com saudade de sua vida pregressa"), o extraficante avalia não ter recorrido corretamente à sua memória, uma vez que resgatara emoções que descaracterizariam e que fragilizariam a construção do seu testemunho. Assim, ao dar seu testemunho de uma forma gramaticalmente errada, o rapaz não estava sendo testemunho - o que, segundo ele mesmo, pôs em questão a autenticidade de sua conversão perante os demais e, de certa forma, também para si.

Além disso, nessa cena, também observamos que a memória e o testemunho não se reduzem a produtos de uma construção social (Pollak \& Schiltz 1991). O caso sugere que essa construção se opera a partir de lógicas com características específicas das quais a própria memória e o próprio testemunho fazem parte. No caso dos CRs, os processos de subjetivação que caracterizam a produção da memória consistem fundamentalmente em aprender a operar com uma gramática do testemunho, a jogar o jogo da conversão. Embora a produção da memória, também nesse contexto, esteja fortemente ligada a reelaborações do passado em função das dinâmicas sociais e políticas nas quais se encontra o aluno/hóspede no presente, estas não são realizadas de uma forma completamente livre e criativa, mas de acordo com as formas sociais que regulam o que pode ser rememorado e como - para que o testemunho seja considerado autêntico.

A partir disso, damos um passo à frente no desenvolvimento de nossa hipótese, argumentando que, no contexto dos CRs, a gramática 
do testemunho produz uma ética específica, através da qual regula os limites e as possibilidades da 'recuperação', da 'conversão', da 'transformação de si', da 'mudança de vida'. Nossa hipótese é a de que a gramática do testemunho funda uma ética da transformação, importante para o reconhecimento da autenticidade das conversões e para a construção da credibilidade dos CRs.

Em sua proposta de uma antropologia da ética, James Faubion (2011), seguindo especialmente os trabalhos de Foucault desenvolvidos a partir do final dos anos 1970 e início dos anos 1980, argumenta que a ética pode ser pensada como um domínio específico, uma esfera de ação que possui seus próprios contornos e lógicas internas. Desse modo, a ética não poderia ser entendida como uma competência de ordem exclusivamente individual, e sim como uma forma social e cultural que produz e delimita uma série de possibilidades de ação. Em diálogo com Faubion, apostamos na ideia de que uma ética da transformação constituiria, na verdade, um domínio específico da ação, que é o domínio da 'transformação', da 'mudança'. Esses não consistem na experimentação de uma transição (suposta ou não) de um estado A para um estado B (como nos ritos de passagem); consistem, antes, em uma forma específica de ser e estar permanentemente no mundo ('estar em mudança', 'ser em mudança'). Desse modo, alunos e hóspedes do CRs pesquisados, ao guiarem suas ações a partir de uma gramática do testemunho, produzem-se como 'sujeitos-em-mudança'.

De maneira geral, mas especialmente nesses contextos de intersecção entre o pentecostalismo e a violência urbana, a maioria dos analistas afirma que, na conversão pentecostal, apresentada pelos atores em narrativas de ruptura, há espaço para uma série de continuidades importantes com as Formas De Vida Nas Quais Estavam Inseridos Antes (Teixeira 2011; Birman \& Machado 2011; Vital da Cunha 2009; Côrtes 2007; Brandão 2017; Minayo \& Ribeiro 2019; entre outros). No entanto, as continuidades e as rupturas que constituem os processos de conversão não são produzidas livremente, de acordo com decisões individuais dos atores. Nossa aposta é a de que tais continuidades são reguladas por uma ética da transformação, que 
define, situacionalmente, as possibilidades de continuidade e de ruptura que produzem uma conversão reconhecida com autêntica. Como vimos anteriormente, o recurso à memória não pode ser realizado de qualquer modo: a ética da transformação delimita as continuidades possíveis e as impossiveis, as rupturas possíveis e as impossíveis.

Diogo Corrêa (2015), por exemplo, argumenta que nas igrejas pentecostais há uma notável hierarquia dos ex. Se, por um lado, um traficante que ocupou altos postos em sua quadrilha pode contar orgulhosamente a sua história de transformação e, eventualmente, trazer para a nova vida algumas experiências importantes da vida anterior, o mesmo não ocorre com 'vacilões' como estupradores e pedófilos, por exemplo. O universo ético da transformação, no caso estudado por Corrêa, torna 'ex-traficante' uma categoria possível dentro do universo pentecostal; enquanto 'ex-estuprador' ou 'ex-pedófilo' tornam-se categorias praticamente impossíveis para a construção de um testemunho público. Veremos, na próxima seção, como os hóspedes do CR do Rio lidavam com tais questões na construção de seus testemunhos.

\section{O orgulho do testemunho na gestão temporal da dor: o sujeito pentecostal em risco}

No contato com pesquisas em CRs não é incomum encontrar simetrias nas narrativas no que se refere a uma situação limítrofe entre vida e morte. Esse discurso é fundamental para a mobilização da entrada e, consequentemente, seu engajamento no tratamento. Ainda assim, é mais categórico a retórica da 'vida por um fio' ou 'a última cartada' quando nos encontramos num terreno religioso que usa a fé como principal instrumento e estratégia de tratamento. Um dos modos de vinculação entre as escolhas e impulsos que os tiraram da liminaridade para a recuperação é o testemunho, em que se gerencia as mudanças de condutas e códigos morais, ao articular e modular as informações da vida pregressa com o progresso da vida convertida e admitida em recuperação.

Como anteriormente apresentado, os testemunhos são a forma de condensar relatos imbuídos de intenções éticas e estéticas, dotados 
de moralidades, de uma economia moral e emocional em que se 'joga' com as modulações de confiança. Confiança essa expressa na construção de perspectivas de fracasso e orgulho, na fuga das assimetrias testemunhais e numa tessitura de reações automáticas e afetiva versus um código moral tido como refletido. A partir de nossos trabalhos de campo, acreditamos que o testemunho não se trata somente de uma narrativa individual, e sim de uma prática coletiva da produção de virtudes, cuja profundidade dos tecidos relacionais é evidenciada. Durante o ato do testemunhar há uma negociação do que se é e de quem se é. Nesse sentido, questionamos: é possível ser ético sozinho nesse contexto? Levamos em conta que os testemunhos estão numa trama relacional em que o sujeito se comunica e performatiza com um grupo a fim de alcançar sua aprovação, operando uma ética específica, relativa à transformação individual que o CR se compromete a produzir.

Para compreender o questionamento que levantamos, pensamos em dois argumentos principais a dialogar com as chaves analíticas da ética da transformação e da gramática do testemunho. Quando entram num CR, eles são encorajados a compartilhar sua história de vida transformada. O sujeito pentecostal se predispõe a uma zona de risco em que, nessa prática coletiva da produção de virtudes, há um grupo que o analisa e julga sua narrativa como coerente, bem intencionada ou verdadeira. Assim, pensamos que a formação de um sujeito pentecostal é a formação de um sujeito em risco. Ao refletirmos sobre esse sujeito que constrói uma discursiva lógica, afetiva, emotiva e espiritual sobre ele para o grupo, argumentamos que há uma gestão da temporalidade da dor presente no testemunho compartilhado, analisando como transformam essa dor em orgulho ('o orgulho de ser ex').

A produção do sujeito pentecostal em risco está também articulada à produção de um espaço que estabelece quem está escutando e julgando e quem está conduzindo. Nessa cena, o sujeito pentecostal faz parte da prática ética, mais do que fazer o outro se converter, coloca-se em risco ao julgamento dos outros ao tentar mostrar códigos morais para ser 'bom sujeito', podendo, ainda assim, ser desmoralizado e desautorizado caso seu testemunho 'não convença'. Costuram-se 
dilemas para encaixar seu testemunho numa prática da virtude e da reflexividade, onde ele deve aprender os limites e as possibilidades do orgulho, numa zona de risco, e deve saber como expor o sofrimento. Quando o sujeito aceita e se predispõe a dar seu testemunho, entra num cenário em que a transformação de si, para ter substância, precisa se enquadrar às formas sociais que estabelecem a delimitação do campo de possibilidades da transformação. De forma geral, nos CRs, não se aceitam fronteiras borradas e a autenticidade da conversão deve ser comprovada durante toda a estadia.

A história a ser contada precisa ter um caminho de fracasso (marcado por crimes e delitos anteriores, casos de 'quase morte') até uma ruptura que abra para um ciclo de sucesso proporcionado pela transformação, conversão, virada de caráter espiritual (da vida em abundância). É importante frisar que não se trata de qualquer crime, pois há critérios em relação à narrativa que é aceita e creditada quando se compartilha a vida pregressa. Ao narrar sua trajetória, com passagens e demarcações de temporalidades, a tônica da dor e do sofrimento é marcante (Machado 2014) - diríamos fundamental - para se entender o processo acentuado em: recepção - escuta coletiva - prática ética.

No que se refere à gestão da temporalidade da dor presente no testemunho, a primeira característica definidora é o arrependimento e esse não vem sem ser seguido do sofrimento. "No fundo do poço tem um resto de água. Mas pra chegar aqui dentro só quando não tem mais água nenhuma. Só quando passar do fundo do poço”. A frase, dita por um hóspede no contexto do CR do Rio de Janeiro, revela que a dor possui muitos significados e quando se chega ao "depois do fundo do poço", o que eles têm para "chamar de seu" é a própria dor. É ela também fator primordial para a experiência do arrependimento, pois, na cosmologia cristã em geral, e pentecostal em particular, não há arrependimento sincero e genuíno se o seu "pecado não te dói". Como já falado por um hóspede no CR do Rio: "a gente sabe quando o cara tá arrependido quando ele chora copiosamente". A frase nos encaminha para uma certa estética do sofrimento desse sujeito pentecostal em risco a entrar na segunda fase de sua gestão de temporalidade cujo 
testemunho precisa ser comprovado também com a emoção. "A dor é uma incisiva figura do mal. Lembrança constante da fragilidade moral do homem. Ela implica uma metafísica”. (Le Breton 2013:105). Trazemos a dor como dimensão fundamental desse transcurso porque a experiência do sofrimento é, nesse contexto empírico, responsável por punir e purificar, assumindo também um tipo de ritualização ${ }^{3}$.

A possibilidade de viver a experiência anterior, mas transformada e atrelada à dimensão da experiência com determinada emoção, liga-os à perspectiva tanto da vergonha quanto do orgulho. Quando se fala da vida passada, a vergonha (junto com o arrependimento) deve estar marcada como uma mancha biográfica. No entanto, o sujeito pentecostal alcançou uma vida transformada devido ao agir de Deus, já que ele não se transforma sozinho. Nessa mudança de status, a divindade é exaltada como autor da ação na vida dele, mas há também sua atitude de deixar-se ser tocado e se colocar como 'vaso na mão do oleiro' (Mauricio Junior 2013). O orgulho é uma emoção acionada nas falas nativas: eles se põem na postura de orgulho em ter um testemunho autêntico para contar, sem deixar de trazer a vergonha também como eixo articulador desse orgulho. Nesse sentido, existem porosidades sobre quando trazer a vergonha ou o orgulho como operador.

O orgulho está, em primeiro lugar, caracterizado na condição de 'ex', orgulho em ter deixado as práticas. Em suas falas a própria palavra é acionada: "tenho orgulho em ter deixado o Espírito Santo agir em minha vida", "tenho orgulho de quem eu sou hoje, em ter abandonado aquele caminho do pecado para fazer a obra de Deus". A passagem de Apocalipse 3:20 ("Eis que estou à porta e bato. Se alguém ouvir a minha voz e abrir a porta, entrarei e cearei com ele, e ele comigo") é trazida como modo de legitimidade da ação pessoal nessa relação entre Deus e o homem, que pressupõe uma autorização humana para que Deus aja.

Percebemos duas perspectivas principais do orgulho: ele não pode ser egocentrado na ação individual - Deus tem que estar no centro - pois ainda que haja a transformação, a categoria da humildade é constantemente evocada para não trazer o orgulho de si para o centro. Ele margeia as emo- 
ções, mas não deixa de estar ali. $\mathrm{O}$ sujeito pentecostal é parte importante dessa interação. A segunda é que, lembremos, esse sujeito está 'em risco', no sentido de ser julgado em suas intenções, então, o orgulho de ser ex deve vir juntamente com a vergonha do que foi vivido anteriormente.

Por isso, não são quaisquer crimes que são bem aceitos, bem vistos ou, no limite, passíveis do perdão dos homens. Existem crimes ou ações que lesam e maculam de tal forma o sentido ético e moral absorvido e expresso por uma determinada comunidade moral que não devem sequer ser mencionados e falados. No contexto estudado, se o passado se refere ao crime de tráfico, por exemplo, ele é bem aceito e passível de ser testemunhado. Mas se o sujeito era pedófilo, estuprador, tido como vacilão, ou X9, fere uma moralidade em que está figurado quase uma impossibilidade de construção do testemunho. Essas condições não devem ser trazidas nem mesmo como elementos de vergonha, não há lugar para a vergonha e o arrependimento, elas devem ser omitidas e banidas da narrativa.

Assim, na construção dos testemunhos nos CRs estudados, surgem questões como: "até que ponto devo ter orgulho de ser ex?", "até onde o meu passado legitima meu presente?". São essas algumas perguntas realizadas no cotidiano dos CRs que questionam em que medida o 'orgulho de ser ex' realmente legitimaria a mudança narrada. Tomemos como exemplo a fala de um hóspede do CR do Rio, que, durante a entrevista, fez questão de marcar uma diferença entre traficante e bandido.

Aqui dentro não usamos o termo bandido, geralmente quem chega quando fala do passado usa as expressões "eu já fui isso" ou "eu formei em tal lugar, tal situação", ou quando dão testemunho falam ex-traficantes, mas nós nunca usamos esses termos ao nos referirmos a eles, até mesmo para desistigmatizar do estereótipo de marginal. Me considero um homem que teve uma passagem pelo tráfico de drogas assim como também teve uma passagem brilhante pela rede pública de ensino, entre outras tantas coisas que fiz na minha vida e não faço mais. Partindo desse princípio me definir como ex-traficante é alǵo vago e preconceituoso. Eu tenho uma visão muito peculiar disso. Não me considero ex-bandido porque não nasci bandido ${ }^{7}$. O bandido para mim é alguém que fez a opção de viver em oposição ao sistema e às autoridades constituídas por ele, de maneira violenta, e egoísta, não se importando com conceitos de moral e ética, e nem 
com o bem estar alheio. Já o traficante nem sempre é um bandido, mas alguém que por alguma situação adversa da vida se viu obrigado, induzido ou seduzido a traficar como maneira de ganhar dinheiro ou prestígio social, o que dentro da cultura de uma classe menos favorecida financeiramente, é aceitável e até compreensível. E o traficante não necessariamente deixa de lado os valores morais e éticos aprendidos como certo e errado, mas mesmo estando fazendo algo fora da lei, guarda os valores deturpados que aprendeu. Mas é claro que a maioria dos traficantes hoje são bandidos, ao contrário de antigamente. Quando falo em antigamente e hoje falo de um fenômeno que está acontecendo em toda a sociedade: a perda dos valores morais, que pode ser vista em todas as classes sociais, e no tráfico, acabou sendo mais prejudicial, porque se não respeito nem os mais velhos não vou respeitar ninguém! Simples assim.

Ao produzir uma clara distinção entre traficantes (pessoas pobres que agem fora da lei, mas não abandonam 'valores morais') e bandidos (pessoas que abandonam 'valores morais' em suas ações totalmente egoístas), o hóspede dialoga diretamente com aquilo que o conceito de sujeição criminal (Misse 2010) descreve. No entanto, na fala do hóspede, a distinção entre traficantes e bandidos não se encerraria em duas formas possíveis de 'viver o crime', mas também apontaria também para os contornos da produção do testemunho. Se, por um lado, para o hóspede, é possível falar, na produção dos testemunhos, em ex-traficantes; por outro, a utilização da expressão ex-bandido seria no mínimo questionável.

\section{Encerramento}

Ao entrar num CR, a lógica de uma trajetória linear já é apresentada aos recém chegados. Quase todos são recebidos com a frase: "Deus tem um projeto de vida para você", o que já pressupõe que a pessoa tem uma vida, uma trajetória até ali, uma história para contar e que esse percurso será modificado e abençoado com um novo projeto de vida. A dinâmica do testemunho começa a ser apresentada nos primeiros dias, quando o novo membro é aceito com sua trajetória antiga e, ao mesmo tempo, também aceita o novo projeto de Deus - o que dá início a um de movimento de temporalidades. Da passagem de um estágio ao outro, em que o estágio anterior não é totalmente abandonado e sim usado 
como sustentação para o início desse novo projeto de vida, o CR se torna um lugar em que escapam de uma realidade - que é, ao mesmo tempo - relembrada a todo momento por seus testemunhos. Essa realidade não pode ser esquecida pois é ela que mobiliza a sua identidade e constrói a sua aceitabilidade e adequação ao universo pentecostal.

Ao se engajar em uma vida evangélica, o testemunho passa por diversas escutas, conduções, negociações, aprovações e julgamentos. "Você acredita nessa conversão?". Eis uma interrogação com a qual lidamos muitas vezes, dentro e fora do trabalho de campo. Para lidar com esse processo, os atores acabam por desenvolver, na prática, uma espécie de ética da transformação, que lhes auxilia, em seu cotidiano, a operar com o 'falso' e o 'verdadeiro', com ‘intenções boas' e ‘intenções más', a reconhecer 'testemunhos autênticos' e 'falsos testemunhos'.

Exatamente por não ter um ponto final, a conversão se liga a e dá sentido e centralidade ao próprio projeto de recuperação. Além de um processo, a conversão acaba não sendo linear; ela é, em certo sentido, circular. A conversão se alimenta da vida anterior (a partir do arrependimento e da própria dinâmica testemunho). Ela se legitima num processo de comparação temporal. Como na fala do hóspede, em que anunciar-se como ex-traficante (diferentemente, para ele, de ex-bandido) constitui uma possibilidade - ainda que limitada e problemática - de comunicar simultaneamente o pecado do passado e a virtude do presente e do futuro. A circularidade da conversão presente nos CRs se contrapõe à conversão como um estado de liminaridade (como nos ritos de passagem). As duas imagens da conversão possuem lastro empírico. E não se trata de afirmar uma ou outra. São duas imagens possíveis da conversão - e que, em muitas ocasiões co-habitam esses espaços, disputando narrativas ou se completando uma à outra. Enquanto a segunda descreveria um sujeito vagando pelos interstícios de dois mundos, a primeira daria destaque à capacidade de agir a partir de uma ética da transformação, regulando as possibilidades de conexão e de ruptura com o passado e de projeção do futuro, regulando as possibilidades de conexão e de ruptura entre mundos. 
Para tratar desse ponto, elaboramos durante o artigo que há uma zona de risco em que o sujeito pentecostal se predispõe a uma prática coletiva da produção de virtudes. As categorias que indicamos como bom, mau, falso e verdadeiro ficam a cargo de um grupo que o analisa e julga sua narrativa e sua performance. É nesse momento que o sujeito pentecostal em risco aciona uma gestão da temporalidade da dor em que deve saber quando transformar sua dor no orgulho de ser ex, sem perder a dimensão individual, espiritual e institucional.

Essas dimensões são espelhadas na forma como modulam suas emoções, seja ao comunicar humildade, vergonha ou orgulho. Em todas essas virtudes Deus tem que estar no centro para se provar a transformação autêntica. A categoria da humildade é constantemente evocada para não trazer o orgulho de si para o núcleo da narrativa. A vergonha é o sinal do arrependimento do que foi vivido anteriormente. O orgulho diz respeito a guinada na fé que permitiu a mudança de vida, esse é o articulador principal que permite operar a vergonha, a dor, o arrependimento e o comportamento de humildade diante da transformação.

Não é qualquer orgulho ou qualquer memória que podem formatar seus testemunhos. Não é qualquer dor que se expõe; e, quando exposta, há formas consideradas adequadas e inadequadas. Não é tudo o que se pode falar, e o que é correto e errado varia de contexto para contexto. A gramática do testemunho e a ética da transformação que ela produz estão atreladas aos contextos específicos de cada CR. Há memórias que são testemunháveis, outras nem tanto. Há memórias que podem ser testemunhadas e que podem, inclusive, incrementar moralmente a narrativa construída: aqueles em que se teve coragem, em que foi macho, em que operou com valores compartilhados pela audiência atual, entre outras possibilidades. E há outras que, se testemunhadas, colocam a credibilidade da narrativa em questão. A transformação proposta pela conversão pentecostal nos CRs é como um jogo de linguagem no qual é preciso aprender a converter-se. 


\section{Notas:}

1 Esse decreto revoga inteiramente o Decreto $n^{\circ}$. 4.345, de 26 de agosto de 2002 e tem o "objetivo de dar orientacões para a aplicação da Lei sobre Drogas (Lei n. 11.343 de 23 de agosto de 2006), promulgada durante o governo Lula da Silva" (cf:https://redesdal.org/blog/f/la-pol\%C3\%ADtica-antidrogas-de-bolsonaro-thiago -rodrigues?blogcategory=Pol\%C3\%ADtica+de+drogas).

2 Citamos aqui algumas das resoluções e decretos importantes na legislação das CTs, tais quais: a RDC 29/2011, Resolução CONAD n01/2015, Portaria n $562 / 2019$, Portaria no 564/2019, Lei 13.840/2019. Destacamos, também, a fala de um dos dirigentes da Confederação Brasileira das Comunidades Terapêuticas, CONFENACT, Célio Barbosa, a qual revela esse campo de disputas entre o que seria a 'verdadeira' e a 'falsa' CT, em que os CRs que pesquisamos se encontram para as federações - como as falsas CTs, diz ele: "Nós tínhamos CT e prestadores de serviço que nã̃o eram CTs, mas atrapalhavam nosso trabalho usando esse mesmo nome. Estivemos numa luta de um ano e quatro meses para mostrar à sociedade e governo que prestamos um serviço diferenciado, de interesse da saúde, assistência social, justiça e educação" (https://www.justica.gov.br/news/comunidades-terapeuticas-sao-regulamentadas). Da mesma forma que o dirigente de um CR que pesquisamos aciona esse discurso de centros que entram para 'se aproveitar' e 'mancham' a imagem de quem faz 'trabalho sério', avaliamos que as críticas, sobre o que se enquadra nos bons testemunhos institucionais, são reinterpretadas de formas diferentes nesses espaços. Esse não é um assunto que se encerra aqui, para os objetivos deste artigo nos limitamos a apontamentos dessas diferenciações entre o que julgam as instituições que merecem ou não serem financiadas, guardando as análises mais específicas desse ponto para uma próxima reflexão.

3 A dor perpassa todo o processo ritual, conferindo sentido a cada etapa. No pensamento cristão, toda essa dor será um dia retribuída pela salvação, pela vida em outro mundo, um céu, então, se trabalha que o sentido de todo o sofrimento é uma recompensa maior. "Compreender o sentido do sofrimento é uma forma de compreender o sentido da vida. Todas as sociedades humanas integram a dor em sua visão do mundo, conferindo-lhe um sentido, e até mesmo um valor, que lhe neutraliza a nudez e, com frequência, até a acuidade [...] A atribuição pelo homem de um sentido a sua dor permite manter intacto seu olhar sobre as coisas, afastar o pânico ou a estupefação quando se é atingido pela adversidade" (Le Breton 2013:109).

\section{Referências:}

AGUIAR, Andrea. 2014. Usuários de crack, instituições e modos de subjetivação: estudos da prática e eficácia terapêutica em uma comunidade terapêutica religiosa (RN). Dissertação de Mestrado. Natal: UFRN.

BIRMAN, Patricia. 2009. "Feitiçaria, resistência e territórios marginais". Mana, 15(2):321-348.

BIRMAN, Patricia \& MACHADO, Carly. 2011. "A violência dos justos: evangélicos, mídia e periferias da metrópole”. RBCS, 27(80):55-69.

BRANDÃO, Beatriz. 2017. Do governo dos corpos ao 'autogoverno das almas': drogas, crime e fé num centro de recuperação pentecostal. Tese de Doutorado. Rio de Janeiro: PUC-RJ. 
BRANDÃO, Beatriz \& CARVALHO, Jonatas. 2016. "Aqui não é uma comunidade terapêutica: entre diversidade e normatividade em tratamentos com usuários abusivos de drogas". Revista Teias, 17(45):63-82.

CORREAA, Diogo. 2015. Anjos de Fuzil: Uma Etnografia da Relação entre Igreja e Tráfico na Cidade de Deus. Tese de Doutorado em Sociologia. Rio de Janeiro: UERJ.

CÔRTES, Mariana. 2012. Diabo e Fluoxetina: formas e gestão da diferença. Tese de Doutorado. Campinas: Unicamp.

DULLO, Eduardo. 2011. "Uma pedagogia da exemplaridade: a dádiva cristã como gratuidade". Religião $\mathfrak{E}$ Sociedade, 31(2):105-129.

2013. A produção de subjetividades democráticas e a formação do secular no Brasil a partir da pedagogia de Paulo Freire. Tese de Doutorado. Rio de Janeiro: MN/UFRJ. . 2014. "Paulo Freire, o testemunho e a pedagogia católica: A ação histórica contra o fatalismo". Revista Brasileira de Ciências Sociais, 29(85):*******. . 2016. “Testemunho: cristão e secular". Religião e Sociedade, 36(2):85-106.

FAUBION, James. 2011. An anthropology of Ethics. Cambridge: Cambridge University.

IPEA. 2016. "Relatório preliminar da pesquisa Perfil das Comunidades Terapêuticas Brasileiras". Boletim de Análise Político-Institucional, 10. Brasília: IPEA. 2017. "Perfil das Comunidades Terapêuticas Brasileiras". Nota Técnica, 21. Brasília: IPEA.

LE BRETON, David. 2013. Antropologia da Dor. São Paulo: Fap-Unifesp.

MACHADO, Carly. 2014, "Pentecostalismo e o sofrimento do (ex-)bandido: testemunhos, mediações, modos de subjetivação e projetos de cidadania nas periferias". Horizontes Antropológicos, 20(42):153-180.

MACHADO, L. P. 2011. Do crack a Jesus: um estudo sobre carreiras de usuários desubstâncias psicoativas em uma comunidade terapêutica religiosa. Dissertação de Mestrado. Salvador: Universidade Federal da Bahia.

MARQUES, António. 2012. O Interior: linguagem e mente em Wittgenstein. Loyola.

MAURÍCIO JÚNIOR, Cleonardo. 2013. Vasos nas Mãos do Oleiro: a constituição do pastor pentecostal. Dissertação de Mestrado. Recife: Universidade Federal de Pernambuco.

MINAYO, C. \& RIBEIRO, F. 2018. "Sentidos del trabajo religioso en contextos marcados por la violencia: estudio en un complejo de favelas en Río de Janeiro”. Salud Colect, 14(2):273-288.

MISSE, Michel. 2010. "Crime, sujeito e sujeição criminal: aspectos sobre uma contribuição analítica sobre a categoria de bandido”. Revista Lua Nova. 79:15-38.

NUNES, M. C. 2016. Firmes nos propósitos: etnografia da internação de usuários de drogas em comunidades terapêuticas. Dissertação de Mestrado. São Carlos: Universidade Federal de São Carlos.

POLLAK, Michael \& SCHILTZ, Marie-Ange. 1991. "Les homosexuals français face au sida. Modifications des pratiques sexuelles et émergence de nouvelles valeurs". Anthropologie et Sociétés, 15(2-3):53-62. 
RUI, Taniele. 2007. Uso de 'drogas', marcadores sociais e corporalidades: uma perspectiva comparada. Dissertação de Mestrado. Campinas: Unicamp. . 2010. "A inconstância do tratamento: No interior de uma comunidade terapêutica". Dilemas: Revista de Estudos de Conflito e Controle Social, 3(8):45-73.

SILVA, Janine. 2010. Interfaces entre Religião e Toxicomania: estudos de caso em duas comunidades terapêuticas religiosas para dependentes quimicos no Rio de Janeiro. Tese de Doutorado. Rio de Janeiro: UERJ.

TEIXEIRA, Cesar P. 2011. A Construção Social do 'Ex-bandido': um estudo sobre sujeição criminal e pentecostalismo. Rio de Janeiro: 7Letras.

. 2013. A teia do bandido: um estudo sobre bandidos, policiais, evangélicos e agentes sociais. Tese de Doutorado. Rio de Janeiro: UFRJ.

. 2016. "O testemunho e a produção de valor moral: observações etnográficas sobre um centro de recuperação evangélico". Religião e Sociedade, 36(2):107-134.

VITAL, Christina. 2009. "Traficantes evangélicos: novas formas de experimentação do sagrado em favelas cariocas". Plural, 15:23-46.

WITTGENSTEIN, Ludwig. 2011. Investigações Filosóficas. Lisboa: Fundação Calouste Gulbenkian.

\begin{abstract}
This work brings together elements of two different researches, carried out by the respective authors, in their doctoral theses on Pentecostal recovery centers. If, on the one hand, the truth of the conversion accounts are not questioned by the researchers, in order to understand in the least asymmetrical way possible the values and the logics in play; on the other hand, the truth of the conversion is recurrently investigated by the researched actors themselves. For most of them, it is crucial to know, for example, who 'really wants to change' and who 'hides behind the Bible.' Eventually they develop a kind of ethics of transformation, which helps them to operate with 'authentic testimonies' and 'false witnesses.' The consequences of possible confusions are extremely sociological, since knowing how to operate with a certain grammar of testimony is fundamental for the construction of the credibility of these centers and, especially, for their expansion.
\end{abstract}

Keywords: Pentecostalism, Recovery Centers, Therapeutic Communities, Ethic, Individual change. 